\title{
Interference with spectrophotometric analysis of nucleic acids and proteins by leaching of chemicals from plastic tubes
}

\author{
L. Kevin Lewis, Michael H. Robson, Yelena Vecherkina, Chang Ji, and Gary W. Beall \\ Department of Chemistry and Biochemistry, Texas State University, San Marcos, TX, USA
}

BioTechniques 48:297-302 (April 2010) doi 10.2144/000113387

Keywords: spectroscopy; polypropylene; plastic additives; microcentrifuge tube; leachate

Absorbance spectroscopy is routinely used to monitor the concentrations of nucleic acids and proteins within solutions and to assess changes in their structure caused by interaction with chemicals or other biomolecules. Biological samples used for such analyses are manipulated and stored in small microcentrifuge tubes (microtubes) composed of polypropylene plus several plastic additives. Here we demonstrate that normal handling of laboratory microtubes causes leaching of light-absorbing chemicals into biological samples that interfere with spectrophotometric measurements. The leached chromophores absorbed UV light strongly at 220 and $260 \mathrm{~nm}$, which are the wavelengths normally used to detect and quantitate proteins and DNA. Some common laboratory techniques, including sonication and PCR, were particularly effective inducers of leaching. The magnitude of the increase in absorbance was dependent upon both exposure time and heat history, with greatest induction after tubes were warmed to temperatures at or above $37^{\circ} \mathrm{C}$. Mass spectrometry revealed that aqueous solutions stored in plastic microtubes accumulate a complex mixture of leached chemicals with molecular masses of 200-1400 Da. Leaching was ubiquitous among commercially available brands of microtubes, indicating a persistent source of error in biomolecule detection and concentration measurements.

\section{Introduction}

Detection and quantitation of nucleic acids within biological samples are routinely performed by monitoring absorbances of solutions at $260 \mathrm{~nm}$. Absorbance spectrophotometry is also a valuable tool for analysis of alterations in the secondary structure of DNA, RNA, and related molecules such as poly(ADPribose) $(1,2)$. This latter assessment takes advantage of the well-known hyperchromicity of DNA and RNA, resulting from intrinsic differences in absorbance among nucleotides and single-stranded and double-stranded species. In addition, absorbance measurements at $220 \mathrm{~nm}$ and $280 \mathrm{~nm}$ are frequently employed to detect and quantitate proteins, while other wavelengths within this range are used to analyze structural changes induced within DNA and RNA upon binding of biomolecules or exogenous chemicals (1,3-5).

Plastic containers used for the storage and manipulation of biological samples are constructed of complex polymer materials containing multiple chemical additives. These additives include supplements such as chemical antioxidants, mold release agents, biocides, and UV-light stabilizers $(6,7)$. Plastic materials may also contain other low-molecular weight chemicals such as residual unreacted monomers and polymer degradation products. Several past studies have demonstrated that additives and other chemicals can leach from plastics into the environment (8-13). A diffusable monomer component within polycarbonate, bisphenol A (BPA), has received much attention in recent years because of its widespread distribution and its ability to act as an endocrine disruptor in animals $(8,9)$. Concern has also been raised about release of formaldehyde, antimony, phthalates and various polymer breakdown products from drinking bottles and other plastic containers (10-13).

Biochemistry researchers use small, 1.5-mL polypropylene microcentrifuge tubes (microtubes) during purification, handling, and storage of nucleic acids, proteins, and other biological samples. Specialty tubes, such as the thin-walled 0.2-mL polypropylene microtubes used for PCR experiments, are also frequently employed. Polypropylene, like other commercial plastics, contains multiple additives that protect and preserve the integrity of the polymer material $(7,12)$. Tubes molded from this plastic have proven invaluable for biological research because of their useful mechanical properties, resistance to extreme temperatures, and low chemical reactivity.

\section{Materials and methods}

UV light absorbance spectroscopy

UV absorbance measurements utilized a SmartSpec 3000 spectrophotometer (Bio-Rad, Hercules, CA, USA) with the scan smoothing function activated. Leachate absorbance experiments described in Figures 1-2 were performed using VWR polypropylene microtubes (Cat. no. 20170-038; Schertz, TX, USA) unless specified otherwise. DNA oligonucleotide Pvu4a (AAATGAGTCACCCAGATCTAAATAA) was obtained from BioServe Biotechnologies (Laurel, MD, USA) and analyzed using $77 \mu \mathrm{g} / \mathrm{mL}$ solutions. DNA concentration calculations were performed using the relationship that 
A
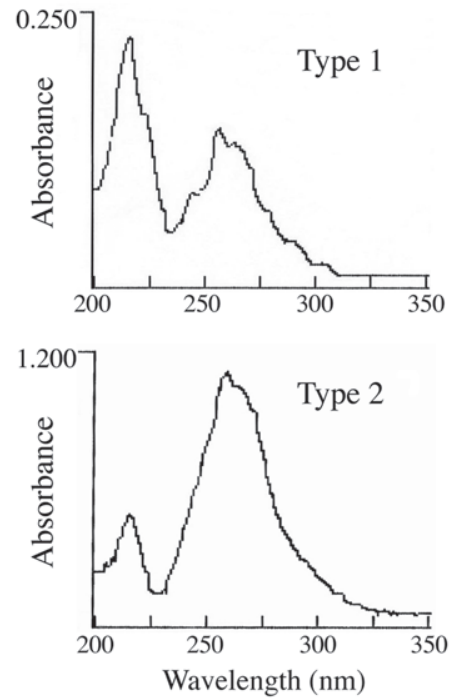

B
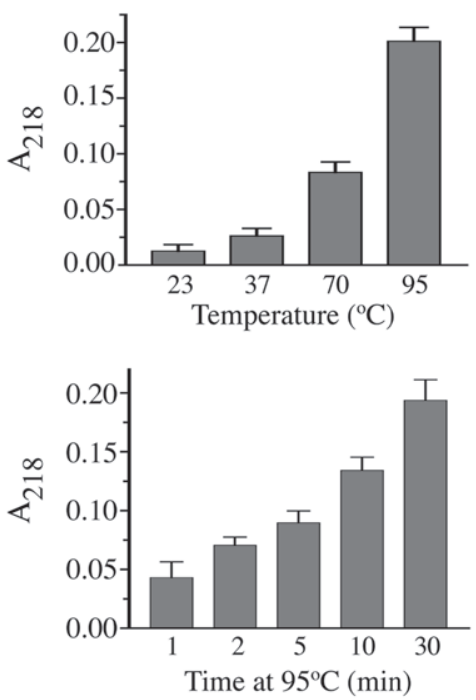

C
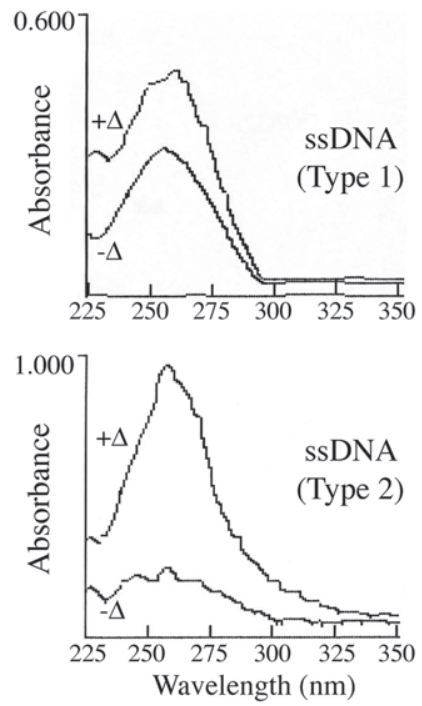

Figure 1. Absorbance characteristics of chemicals leaching from common laboratory microtubes. (A) Brief heating $\left(30 \mathrm{~min}, 100^{\circ} \mathrm{C}\right)$ released UV-absorbing chemicals into water that produced either type 1 or type 2 spectra. Most commercially available tubes are type 1 . Microtubes: type 1, VWR, Cat. no. 20170-038; type 2, Ambion, Cat. no. 12400. (B) Temperature- and time-dependence of 218-nm peak formation in the most common tube type. Error bars indicate SD. (C) Alteration of absorbance spectra of single-stranded oligonucleotide DNA (25 nucleotides) after incubation for $30 \mathrm{~min}$ at $95^{\circ} \mathrm{C}$. $-\Delta$, no heat; $+\Delta$, heated sample.

an $\mathrm{A}_{260}$ of 1.0 corresponds to a concentration of $33 \mu \mathrm{g} / \mathrm{mL}$ for single-stranded DNA oligonucleotides (1). Chloroform, DMSO, and methanol were obtained from Sigma-Aldrich (St. Louis, MO, USA). PCR was simulated using a 2720 Thermal Cycler from Applied Biosystems (Foster City, CA, USA). Sonication was performed using a Vibracell VC130 sonicator (Sonics \& Materials, Inc., Newtown, CT, USA) set at an amplitude of 30 . Standard microcentrifuge tubes tested in these studies included the following brands and catalog numbers: VWR (Cat. no. 20170-038), Ambion/Applied Biosystems (Cat. nos. 12400 and 12300), Sarstedt (Fisher, Cat. no. 50809206; Newton, NC, USA), Axygen MCT-175-A (VWR Cat. no. 10011-718), Intermountain Scientific Corporation (Cat. no. C-3261-3; Kaysville, UT, USA), Vangard (Cat. no. CN065S-GT; Vangard International, Inc., Neptune, NJ, USA), and Fisherbrand (Fisher, Cat. no. 02-681-376). Two tubes recently advertised to contain fewer mold release agents (Axygen MCT-150-C; VWR 10011-700) or plasticizers, slip agents, and biocides (Cat. no. 022364111; Eppendorf, Hauppauge, NY, USA) were also tested. PCR tubes (0.2-mL, thin-walled) tested included the following brands: Labcon (VWR, Cat. no. 21070-012), Ambion/
Applied Biosystems (Cat. no. AM12225), Nalgene (Genunc, Cat. no. \#250865; Lima, OH, USA), ISC BioExpress (GeneMate, Cat. no. C-3257-1), and VWR brand tubes (Cat. no. 20170-010).

\section{GC-mass spectrometry}

An Agilent Technologies (Santa Clara, CA, USA) model $6890 \mathrm{~N}$ gas chromatograph (GC) equipped with a model $5973 \mathrm{~N}$ mass selective detector was utilized for analysis of the leachate for compounds with molecular masses up to 200. Analytes were separated using an Agilent Technologies HP-5MS $30 \mathrm{~mm} \times 0.25 \mathrm{~mm}$ capillary column with a $5 \%$ crosslinked phenylmethylsiloxane stationary phase. The oven temperature was held initially at $45^{\circ} \mathrm{C}$ for $6 \mathrm{~min}$ and then ramped to $200^{\circ} \mathrm{C}$ at $8^{\circ} \mathrm{C} / \mathrm{min}$. The split ratio was $20: 1$.

\section{Electrospray ionization}

mass spectrometry

Positive-ion and negative-ion electrospray ionization experiments were performed using the conventional electrospray ionization source of an LCQ Classic (Thermo-Fisher, Waltham, MA, USA) operating at $\mathrm{m} / \mathrm{z}$ range of 200-2000. Sample solutions were introduced into the electrospray ionization source using a $5-\mu \mathrm{L}$ sample loop. Methanol with a flow rate of
$50 \mu \mathrm{L} / \mathrm{min}$ was used as the push solvent. The mass spectrometer experimental conditions were as follows: sheath gas flow rate, 75 (arbitrary units); aux gas flow rate, 20; and capillary temperature, $200^{\circ} \mathrm{C}$. Spray voltages were $5 \mathrm{kV}$ (positive ion mode) and $3.5 \mathrm{kV}$ (negative ion mode).

\section{Results and discussion}

As part of a recent spectrophotometric study of the efficiency of sedimentation of DNA and clay particles by centrifugation (14), we observed that prolonged high-speed centrifugation and concomitant warming of plastic microtubes caused an unexpected increase in UV absorbance at $260 \mathrm{~nm}$. To investigate the phenomenon more comprehensively, absorbances of several commercially available brands of standard microtubes containing $1 \mathrm{~mL}$ deionized water were analyzed before and after heating the tubes for $30 \mathrm{~min}$ in a $100^{\circ} \mathrm{C}$ heating block. New absorbance peaks appeared at approximately 220 and $260 \mathrm{~nm}$ upon heating, producing two consistent patterns (Figure 1A). Most tubes displayed the type 1 spectrum, with a large peak near $220 \mathrm{~nm}$ (218 nm maximum) and smaller peak near $260 \mathrm{~nm}(259 \mathrm{~nm}$ maximum). In a minority of tubes, the peak near $260 \mathrm{~nm}$ was dominant. No other 
A
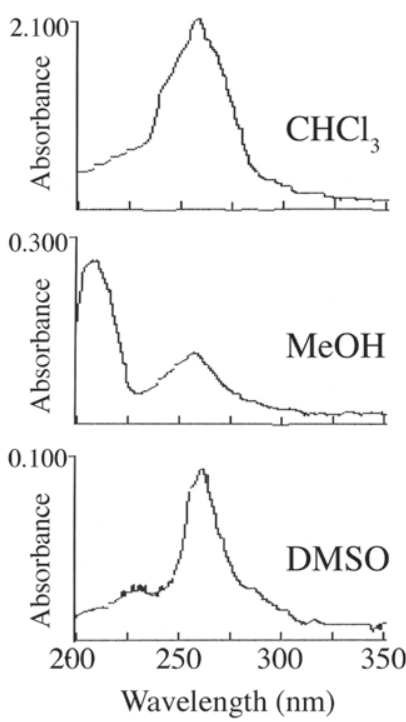

B
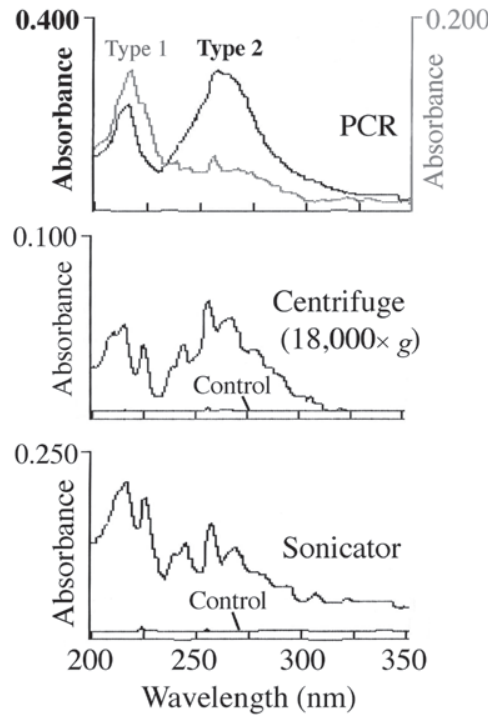

C

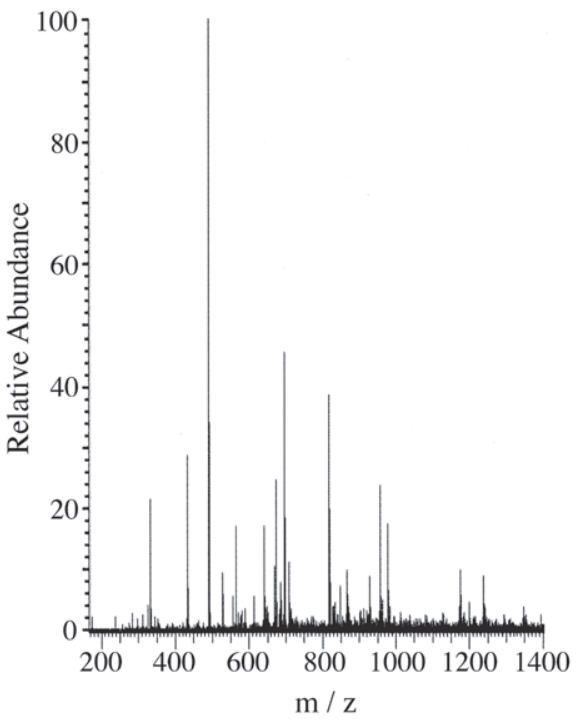

Figure 2. Impact of common biochemistry laboratory procedures and solvents on leachate formation within polypropylene microtubes. (A) Spectra observed for leachates produced, without heating, after 30 min in common biochemistry solvents chloroform $\left(\mathrm{CHCl}_{3}\right)$, methanol (MeOH), and DMSO. (B) Seepage of UV-absorbing materials from thin-walled 0.2-mL tubes into water is substantial after 30 cycles of PCR (top panel). Modest leaching was also observed after centrifugation of standard $1.5-\mathrm{mL}$ tubes for $30 \mathrm{~min}$ at $18,000 \times \mathrm{g}$ or mild sonication for $5 \mathrm{~min}$. Control, untreated solution. PCR microtubes: type 1, Ambion, Cat. no. AM12225; type 2, Nalgene Genunc, Cat. no. 250865. (C) Electrospray mass spectra of water leachate (30 min, $\left.95^{\circ} \mathrm{C}\right)$ from type 1 (VWR, Cat. no. 20170-038) microtubes.

absorbance peaks were observed within the wavelength range of $200-600 \mathrm{~nm}$ in any of the tubes tested.

A representative tube from the most common group - type 1 -was used for subsequent studies of leaching from standard $1.5-\mathrm{mL}$ tubes except where noted otherwise. The magnitude of leachate peak absorbance could be substantial (up to 1.0-2.0 absorbance units) and was temperature-dependent (Figure 1B, top panel). Modest chromophore leaching was detectable after $30 \mathrm{~min}$ at $37^{\circ} \mathrm{C}$, the temperature used for most enzymecatalyzed reactions in biochemistry, but seepage was strongest at higher temperatures $\left(70^{\circ} \mathrm{C}\right.$ and $\left.95^{\circ} \mathrm{C}\right)$. These high temperatures are often employed to heat-inactivate enzymes, denature DNA, and perform other reactions such as PCR that involve thermostable enzymes (described below). The effect was time-dependent and rapid, being readily observable $<5$ min after exposure to elevated temperatures (Figure $1 \mathrm{~B}$, bottom panel).

Nucleic acids absorb light strongly at $260 \mathrm{~nm}$ and absorbance at this wavelength is commonly employed to detect and quantitate DNA (1). Proteins absorb UV light at $220 \mathrm{~nm}$ due to the presence of double bonds within amino acid carbonyl groups. Most proteins also absorb light at $280 \mathrm{~nm}$, with peak height at $280 \mathrm{~nm}$ dependent primarily upon the fraction of tryptophan and tyrosine amino acids within the protein. To examine how biomolecule absorbance spectra are shifted by heating in microtubes, aqueous solutions containing a single-stranded DNA oligonucleotide (25 nucleotides in length) were scanned before and after heating for $30 \mathrm{~min}$. As shown in Figure $1 \mathrm{C}$, heating caused a substantial increase in absorbance at $260 \mathrm{~nm}$ in type 1 tubes. This increase, from 0.31 to 0.48 , is equivalent to an apparent change in DNA concentration from 10.2 to $15.8 \mu \mathrm{g} / \mathrm{mL}$, an overestimate of $55 \%$. In the type 2 tubes analyzed in Figure $1 \mathrm{C}$, a larger increase in absorbance was observed (0.24 to 0.96$)$, suggesting a change from 7.9 to $31.7 \mu \mathrm{g} / \mathrm{mL}$, resulting in an overestimate of $300 \%$. No increase in absorbance occurred when heating was performed using a glass test tube as control.

Most plastic additives and their degradation products are small- and mediumsized organic molecules and therefore may seep most efficiently into organic solvents. We observed that leaching was variable but strong at room temperature (i.e., without heating) within tubes containing the common biochemistry solvents chloroform, methanol, or DMSO (Figure 2A). Incubation with chloroform-often used for DNA extractions-produced the highest leachate response of all solvents tested (absorbance > 2.0). Peak patterns displayed by the organic solvent leachates were typically not identical to those produced in aqueous solutions, which is likely a reflection of differential solubilities of the leachate chemicals and changes in solvation effects on absorbance.

The impact of common laboratory methods on chromophore leaching was also evaluated. PCR, one of the most frequently employed techniques in biochemistry, uses thin-walled polypropylene tubes manufactured specifically for this procedure. Several brands of PCR tubes containing $150 \mu \mathrm{L}$ water were all found to leach light-absorbing materials after exposure to a standard 30 -cycle program (30 s at $95^{\circ} \mathrm{C}, 30 \mathrm{~s}$ at $60^{\circ} \mathrm{C}$, and $2 \mathrm{~min}$ at $72^{\circ} \mathrm{C}$ ) on a PCR thermocycler (Figure $2 \mathrm{~B}$, top panel). Absolute absorbances achieved were strong but variable, depending upon the brand tested, and could be classified into two patterns as before. Other laboratory 
procedures, such as centrifugation in a microcentrifuge at $18,000 \times g$ for $30 \mathrm{~min}$ or mild sonication for $5 \mathrm{~min}$ (Figure $2 \mathrm{~B}$, bottom panels), also stimulated leaching. Increasing the centrifugation or sonication times produced higher absorbances and also greater warming of the tubes, suggesting that the increase in temperature is the primary leaching stimulus.

Biochemists routinely visualize DNA and RNA in gels by staining with the fluorophore ethidium bromide, and DNA is quantitated in solutions using fluorophores such as Hoescht 33258. We did not detect interference in ethidium bromide staining or Hoescht 33258-based DNA quantitation assays by leachates (data not shown), possibly because of the specificity of these chemicals for DNA and because their emissions are at visible wavelengths (above $400 \mathrm{~nm}$ ) and leachate chemicals do not have strong interactions with light at these wavelengths.

We also performed experiments to test whether leachate chemicals are coprecipitated during precipitation of DNA with ethanol, which is a routine procedure in many molecular biology labs. Using type 1 microtubes containing high amounts of leachate produced by heating using our standard method $\left(\mathrm{H}_{2} \mathrm{O}, 30 \mathrm{~min}\right.$, $100^{\circ} \mathrm{C}$ ), we measured initial absorbances and then performed DNA precipitations according to a standard protocol utilizing sodium acetate and ethanol (1). The $\mathrm{A}_{220}$ of the initial leachate solutions was 0.376 $\pm 0.015( \pm S D)$ and became $0.010 \pm 0.009$ after the precipitated material was resuspended. Using the same procedure, doublestranded plasmid DNA was precipitated with $90 \%$ efficiency, indicating that the method used could effectively precipitate DNA molecules. These results demonstrate that the light-absorbing leachate materials do not readily co-precipitate with DNA. This finding is not unexpected because (i) the mass spectrometry data revealed that chemicals leached from microtubes have low molecular weights $(<1400 \mathrm{Da})$ and (ii) small molecules, including very small DNAs, are not precipitated efficiently out of aqueous solutions.

The chemical composition of the water leachates was investigated using electrospray mass spectrometry, a non-fragmenting technique with an approximate detection range of 200-2000 Da. This analysis revealed that water leachates are heterogeneous mixtures of small molecules with masses between 200 and $1400 \mathrm{Da}$ (Figure 2C). Use of GC-mass spectrometry, which detects the presence of smaller molecules, did not identify any components with masses $<200 \mathrm{Da}$ when the water leachate was dried and resuspended in either acetone or diethyl ether. However, after direct extraction of the water leachate into diethyl ether, a major component with a mass of $134 \mathrm{Da}$ was detected and predicted to correspond to 2,4-dimethylbenzaldehyde or 2-ethylbenzaldehyde.

In this work, we have demonstrated that plastic microtubes used in biochemistry research release chemicals into aqueous solution that absorb light at DNA and protein absorbance peak maxima during normal use. Leaching was promoted by procedures that cause warming of the tubes such as high-speed centrifugation, sonication, and incubation at temperatures $\geq 37^{\circ} \mathrm{C}$.

Commercial polymers typically contain several different additives, many of which contain double bonds and aromatic groups that cause them to absorb UV light $(6,7)$. Many additives, such as antioxidants and UV protectants, act as sacrificial defenders that become chemically altered and/or degraded during polymer heating and processing and also over time as the plastic ages $(6,7,15,16)$. The large size heterogeneity of the materials diffusing from the plastic microtubes suggests that leachates

\section{BD Biosciences flow cytometry systems}
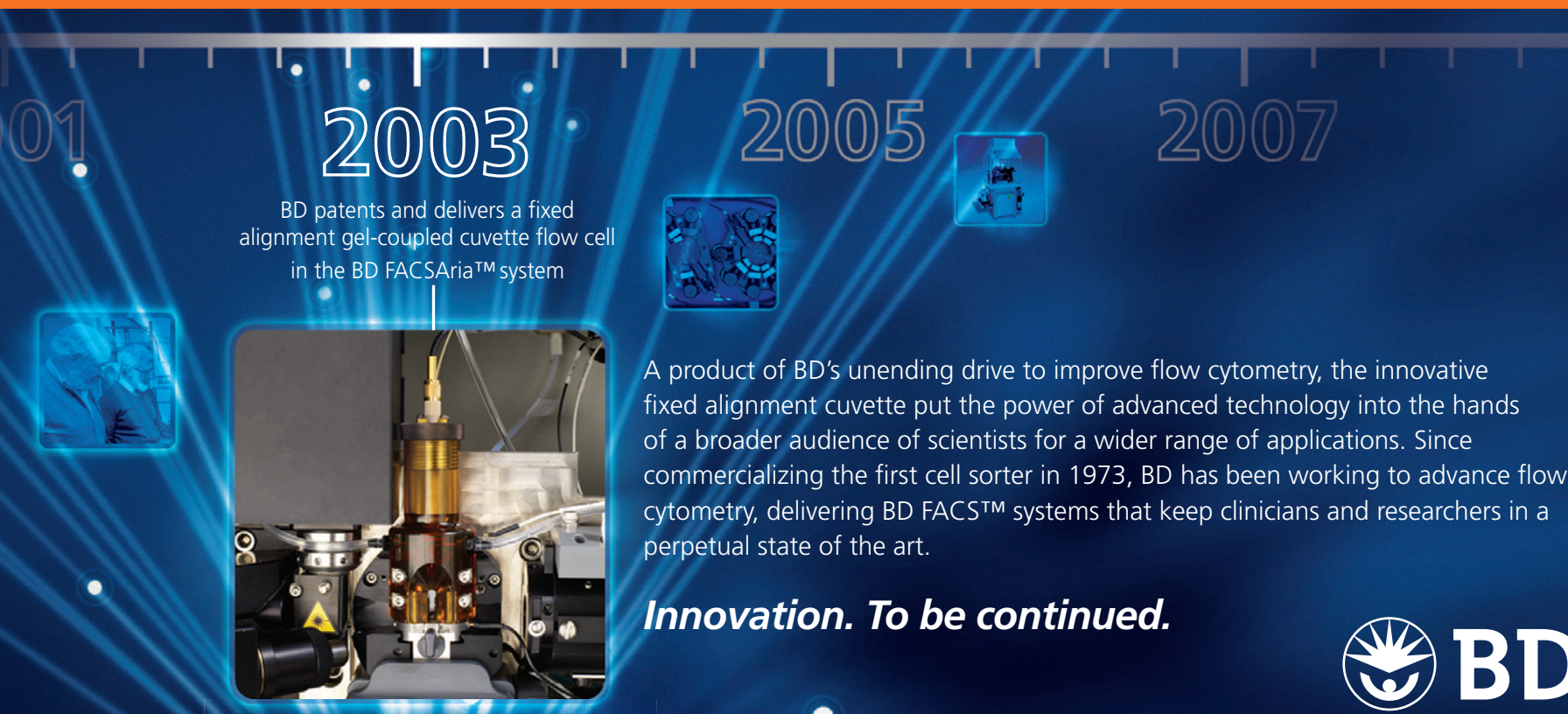

Innovation. To be continued. 
are composed of multiple additives and their breakdown products. In widely available polymers such as polypropylene, the processing, heating, and oxidation histories of different preparations will vary, as will the effects of aging. It is likely that the variations in $U V$ absorbance spectra of the different tubes (Figure 1A and Figure 2B) are a reflection of this variability in polymer compounding methods and stress history, as well as in the types and quantities of additives used. Some companies have recently begun manufacturing microtubes that contain a reduced number of chemical additives. The precise impact of such changes on the distribution of light-absorbing and nonchromophoric chemicals in the plastic tubes-as well as their chemical and mechanical properties-is not clear. However, the magnitude of leaching observed using our standard assay $\left(\mathrm{H}_{2} \mathrm{O}, 30 \mathrm{~min}, 100^{\circ} \mathrm{C}\right.$; data not shown) was reduced in two such tubes (see "Materials and methods" section). Biochemistry labs frequently employ plastic 96-well microtiter plates, usually made from polystyrene, to perform enzyme assays and other high-throughput procedures. In tests using polystyrene 96-well plates (Cat. no. 353075; BD Biosciences, San Jose, CA, USA) and our standard assay $\left(\mathrm{H}_{2} \mathrm{O}, 30 \mathrm{~min}, 100^{\circ} \mathrm{C}\right)$, we did not detect increased absorbance at either 220 or $260 \mathrm{~nm}$. This suggests that polystyrenebased materials used in biochemistry labs may be different from polypropylene in this regard. However, such investigations are complicated by the fact that many microtiter dishes contain special surface coatings for tissue culture that may alter leachate responses; therefore, further study is needed.

Biochemistry and molecular biology labs routinely use $A_{260}$ measurements to quantitate DNA and $A_{220} / A_{280}$ readings for detection of proteins. UV absorbance is also monitored to analyze changes in secondary structure of individual nucleic acids, as well as analyze alterations induced within DNA and RNA upon binding with other molecules (3-5). Researchers frequently heat samples at elevated temperatures (e.g., performing enzyme-catalyzed reactions, denaturing DNA, lysing cells, heat-inactivating enzymes, etc.), which stimulates the release of UV-absorbing polypropylene leachates. McDonald et al. reported that additives leached from some commercially available polypropylene microtubes can inhibit the enzyme human monoamine oxidase-B (hMAO-B) (17). Their results demonstrate that leachates may interfere with functional assays for a few specific biomolecules, but our observations suggest that a more widespread problem exists.

The ubiquitous nature of leaching among the different brands of microtubes tested indicates that this contamination is a persistent source of error in molecular biology experiments utilizing UV spectroscopy. The magnitude of such errors can be substantial, since leachates typically exhibited $\mathrm{A}_{260}$ readings between 0.2 and 2.0 absorbance units. Mitigation of the problem in the future will require use of plastics that retain the positive qualities found in existing tubes-such as low chemical reactivity, high temperature stability, and resistance to oxidationbut which contain fewer chromophoric additives. In this regard, it is encouraging that some manufacturers (see "Materials and methods" section) have announced new polypropylene-based tubes that contain fewer additives, though the impact of such changes on the beneficial characteristics and lifespan of the tubes is not yet clear.

\section{Acknowledgments}

We thank Mehdi Moini for expert technical analysis using electrospray mass spectrometry. This work was supported by the National Institutes of Health $(\mathrm{NIH}$; grant no. 1R15AG028520-01A1) and the Welch Foundation (grant no. AI 0045). This paper is subject to the NIH Public Access Policy.

\section{Competing interests}

The authors declare no competing interests.

\section{References}

1.Sambrook, J. and S.W. Russell. 2001. Molecular Cloning: A Laboratory Manual, 3rd ed. Cold Spring Harbor Laboratory Press, Cold Spring Harbor, NY.

2.Minaga, T. and E. Kun. 1983. Spectral analysis of the conformation of polyadenosine diphosphoribose; Evidence indicating secondary structure. J. Biol. Chem. 258:725730 .

3.Marty, R., C.N. N'soukpoé-Kossi, D. Charbonneau, C.M. Weinert, L. Kreplak, and H.-A. Tajmir-Riahi. 2009. Structural analysis of DNA complexation with cationic lipids. Nucleic Acids Res. 37:849-857.

4.Minetti, C.A., D.P. Remeta, and K.J. Breslauer. 2008. A continuous hyperchromicity assay to characterize the kinetics and thermodynamics of DNA lesion recognition and base excision. Proc. Natl. Acad. Sci. USA 105:70-75.

5. Ghasemi, J., S. Ahmadi, A.I. Ahmad, and S. Ghobadi. 2008. Spectroscopic characterization of thiazole orange-3 DNA interaction. Appl. Biochem. Biotechnol. 149:9-22.

6. Pfaendner, R. 2006. How will additives shape the future of plastics? Polymer Degrad. Stabil. 91:2249-2256.

7.Zweifel, H. 2009. Plastics Additives Handbook, 6th ed. Hanser Publications, Munich.

8. Vandenberg, L.N., M.V. Maffini, C. Sonnenschein, B.S. Rubin, and A.M. Soto. 2009. Bisphenol-A and the great divide: a review of controversies in the field of endocrine disruption. Endocr. Rev. 30:75-95.

9. Oehlmann, J., M. Oetken, and U. SchulteOehlmann. 2008. A critical evaluation of the environmental risk assessment for plasticizers in the freshwater environment in Europe, with special emphasis on bisphenol A and endocrine disruption. Environ. Res. 108:140-149.

10. Mendell, M.J. 2007. Indoor residential chemical emissions as risk factors for respiratory and allergic effects in children: a review. Indoor Air 17:259-277.

11. Shotyk, W., M. Krachler, and B. Chen. 2006. Contamination of Canadian and European bottled waters with antimony from PET containers. J. Environ. Monit. 8:288292.

12.Malo, J.L., A. Cartier, L. Pineault, M. Dugas, and A. Desjardins. 1994. Occupational asthma due to heated polypropylene. Eur. Respir. J. 7:415-417.

13. Heudorf, U., V. Mersch-Sundermann, and J. Angerer. 2007. Phthalates: toxicology and exposure. Int. J. Hyg. Environ. Health 210:623-634.

14.Beall, G.W., D.S. Sowersby, R.D. Roberts, M.H. Robson, and L.K. Lewis. 2009. Analysis of oligonucleotide DNA binding and sedimentation properties of montmorillonite clay using ultraviolet light spectroscopy. Biomacromolecules 10:105-112.

15. Marcato, B., S. Guerra, M. Vianello, and S. Scalia. 2003. Migration of antioxidant additives from various polyolefinic plastics into oleaginous vehicles. Int. J. Pharm. 257:217-225..

16. Begley, T.H., J. Brandsch, W. Limm, H. Siebert, and O. Piringer. 2008. Diffusion behaviour of additives in polypropylene in correlation with polymer properties. Food Addit. Contam. Part A Chem. Anal. Control Expo. Risk Assess. 25:1409-1415.

17. McDonald, G.R., A.L. Hudson, S.M.J. Dunn, H. You, G.B. Baker, R.M. Whittal, J.W. Martin, A. Jha, et al. 2008. Bioactive contaminants leach from disposable laboratory plasticware. Science 322:917.

Received 21 December 2009; accepted 26 February 2010.

Address correspondence to L. Kevin Lewis, Chemistry and Biochemistry, Texas State University, 601 University Drive, San Marcos, TX 78666, USA.e-mail: LL18@txstate.edu 